QMR

22,5

\title{
Qualitative research for breakthrough innovation
}

\section{6}

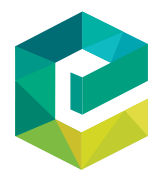

Qualitative Market Research: An International Journal Vol. 22 No. 5, 2019 pp. $796-804$ c) Emerald Publishing Limited 1352-2752 DOI 10.1108/QMR-06-2018-0063

\section{Introduction}

Organisational innovation is desirable because it can create extra competitiveness in firms as well as revenue growth and additional jobs in society (Roper, 1997; Design Council, 2011). At a product level, innovation objectives can include a desire to match competitors' product offerings, replace or enhance existing products, extend product ranges, produce products aimed at new markets, reduce production costs, improve product quality and produce environmentally friendly products (Roper, 1997). Innovation is sought after by firms because it is a good source of incremental financial turnover in manufacturing businesses. For example, in the UK, it was found that turnover from new products, from new innovations and from improved products equalled about 12.5 per cent of manufacturers' annual turnover in 2001 (Laursen and Salter, 2006). Innovation can also ensure that firms remain relevant to customers rather than obsolete and thereby stay competitive in a changing market (Tushman and Nadler, 1986). Despite its mystique, innovation can easily be fostered and encouraged within organisations as the calculated outcome of forward thinking leadership (Tushman and Nadler, 1986). This current paper outlines how qualitative research can be used to create breakthrough innovation.

The aim of the current paper is therefore to take ideas from the literature on innovation, creativity, idea generation and qualitative research and synthesise these into a roster of research aimed at the generation of breakthrough innovation.

In an organisational context, breakthrough innovation can be defined as the concrete implementation of novel creative ideas which advance group objectives in a groundbreaking manner. At the level of strategic entrepreneurship the aim of idea generating research would thus be to facilitate the emergence of innovation within one or more of the following (Kuratko and Morris, 2018):

- the business model;

- the organisational strategy;

- product/service offerings;

- target audiences/markets; and

- the organisation's internal structure, processes and capabilities.

Innovation can be incremental, where small changes are made which extend, modify or improve whatever processes or products are being modernised. The move from open top cars e.g. the Model T Ford to cars with fully enclosed cabs e.g. General Motors 1906 Cadillac, is an example of such an incremental innovation (Tushman and Nadler, 1986). Other innovations can synthesise multiple improvements - perhaps adopted from several different competitors - into one process or product so that it becomes leading in its class (Tushman and Nadler, 1986). Radical or discontinuous innovations can involve step changes in technology and Tushman and Nadler (1986) give the example of the move from piston powered airplane engines to jet engines as an example of this. However, such innovations may not initially be recognised as

This paper forms part of a special section "Fetishism, commodity fetishism, consumption and desire", guest edited by Anoop Bhogal-Nair Anoop and Mark Tadajewski. 
radical because, for example, the first jet planes were no better than piston powered planes and the first digital photographs were worse in quality than existing photographic techniques as exemplified and manufactured by Kodak. This means that the initial evaluation of new innovations can be inaccurate and has to be carefully orchestrated.

Innovations in business or service processes change the manner in which the organisation deals with the steps involved in product or service delivery. For example, steps can be streamlined so as to make delivery faster and more efficient which improves the quality or speed with which customers are dealt with. Business process improvements can be made via the application of structured ways of examining and modifying service delivery such as those involved in the Lean Six Sigma methodology where for example a hospital has made improvements in clinical processes and service excellence (Craven et al., 2006). As another example, this methodology can be used to implement incremental improvements in processes such as more timely book replacement work in a university library (Boddy et al., 2010).

Queuing systems have also been modified using this business process improvement technique. For example, the standard customer queue in a bank is nowadays a single queue leading to multiple tellers whereas previously it consisted of multiple queues, one for each bank teller. The problem with multiple queues was that if one teller was slow or had to deal with a difficult customer then everyone in that queue was delayed whereas later customers might join a quicker queue and be seen in a timely manner. Deciding which queue to join was a hit and miss decision.

This queuing system was unfair in as much as some customers might be delayed despite coming earlier than other customers and this would lead to customer dissatisfaction. The reduction of queuing into a single queue which was first developed I believe at ANZ bank in Australia, was counter-intuitive - after all how can a single queue be quicker than three or four queues? Previously, banks with slow moving queues would simply put on another teller creating an additional queue. The move to a single queuing system served by multiple tellers was an example of process innovation. However, it involved only a temporary advantage for ANZ because the system was easily copied and has become the standard way of managing customer queues around the world in banks, retail outlets and other customer facing organisations. These process innovations thus change the way and improve the manner in which products or services are delivered. The single queuing system needs fewer tellers and so is more cost efficient for the bank and it simultaneously delivers quicker customer service.

Breakthrough innovation thus consists of two stages, firstly the generation of original ideas and secondly the production of those ideas into concrete form. However, it should be noted that even if an organisation embodies the key antecedents to the creation of entrepreneurship such as a supportive management culture, employee autonomy and worker time availability (Kuratko and Morris, 2018) there still remains the problem of generating viable ideas for innovation in the first place. The aim of this paper is therefore to describe how the creation of new ideas and the evolution of those ideas into reality can be deliberately achieved via qualitative research.

\section{Discussion}

According to the literature concerning the building of an organisational culture which stimulates creativity and innovation, one of the key ingredients is employee autonomy in terms of flexibility and freedom (Martins and Terblanche, 2003). It follows from this that research activities which seek to stimulate maximal creative idea generation should entail giving research participants a sense of autonomy encompassing flexibility and freedom.

This is indeed the case because in using brainstorming techniques for generating multiple idea formation, one of the rules is that no criticism of proposed ideas is allowed at 
QMR 22,5

798 the idea generation stage (Boddy, 2012; Bashford, 2004; Taylor et al., 1958). Brainstorming techniques are often recommended for generating multiple creative ideas (Barrett, 1978; Schwartz, 1991; Hollins, 1999) and using the nominal group technique can also help generate ideas quickly (Claxton et al., 1980; Gregerman, 1981; Boddy, 2012).

Furthermore, this benefit of research participant freedom in generating creativity implies that free-ranging discussion techniques such as those involved in social constructivist style focus group discussions rather than positivist style focus group interviews (Boddy, 2005b, 2005a) should be utilised. The nominal group technique - where people work alone and in silence for idea generation - can also be useful because this removes the social desirability (Fisher, 1993) filter from research participants, which frees them to put forward ideas which may otherwise never be mentioned.

Diverse and cross-functional teams have been found to stimulate innovation and creativity (Martins and Terblanche, 2003; Østergaard et al., 2011) while alliances can also be a source of innovation generation (Dunlap-Hinkler et al., 2010) as the cross-fertilisation stimulated can feed into the innovation process. Further, a diversity of skill sets and knowledge has been found to be an influential predictor of innovation (West, 2002). Therefore, a diverse and multi-disciplinary research group composition may stimulate idea generation as long as social desirability bias does not come into play. Furthermore, teams which span organisational boundaries and are for example comprised of users (customers) and suppliers may facilitate innovation (Laursen and Salter, 2006) and therefore qualitative research which seeks to foster innovation should be comprised of multiple actors in the organisational environment as well as being from multiple departments (e.g. design, sales, marketing, production) within the organisation. Such multiple participants should help ensure that the innovation research group has a maximum ability to acquire information about customers, competitors and technology and thus is an effective learning system as defined by Tushman and Nadler. These ingredients provide the basis for sustained organisational innovation (Tushman and Nadler, 1986). Innovation research participants with good discovery skills, people who are prepared to question the status quo and can identify opportunities from observing behaviour in customers (Dyer et al., 2009) would be useful to have as group members because they are able to gain insights concerning new ways of getting things accomplished.

In terms of the optimal breadth of search for sources of innovation, Laursen and Salter (2006) provide some guidance because they find that innovation performance is subject to decreasing incremental returns after about six or seven sources of ideas have been investigated, while examining more than eleven sources may even be detrimental. The six or seven most commonly used sources of information for innovation in the UK manufacturing sector are suppliers, clients, health, safety and environmental standards, fairs and exhibitions, technical standards and competitors (Laursen and Salter, 2006). This has implications for:

- Whom to invite to take part in qualitative innovation research?

- What stimulus materials to use?

- What research methods to use? Where and when to convene research sessions such as focus group discussions using e.g. Ethnographic approaches? (Boddy, 2011; Stafford, 1993).

In terms of potential participants in the research process, representatives from suppliers can be invited to periodically take part in the qualitative innovation research being implemented, in order to discuss possible avenues for innovation. In this case, stimulus 
materials may include existing supplies e.g. components/materials used as prompts to discuss how these may be improved upon or replaced by alternatives. Research sessions should probably be convened away from the suppliers' premises so as to give them uninterrupted time to consider alternatives and to remove participants from potential sources of social desirability bias such as in-house vested interests in maintaining current materials/supplies.

Other potential participants in the research process could include customers. In this case, stimulus materials may include current products/services to establish any potential weaknesses or negatives in these that could be improved upon. Discovery of customer's existing ways of interacting with current products/services may be established via ethnographic approaches to research such as visiting customers in the places where they actually use the products/services and at the time they are using them. This may uncover manners of use which are suggestive of possible unmet customer needs. Including sales, marketing and market research staff in the qualitative innovation research being implemented can also increase customer insights from pre-existing knowledge of customer needs and product usage.

Research sessions may further include "market investigations" such as research group trips to trade fairs and product exhibitions where similar and associated products/services can be investigated for ideas which can also be applied to the organisations' own products and services. Research participants in these market investigations could include the organisations own personnel, as well as personnel from customers and suppliers because each group may have different ways of looking at what is on offer. Thereby the range of possible innovations which may result from such market investigations is maximised. Products of interest at the trade fairs and exhibitions may be purchased and brought back for use as stimuli for discussion at further research sessions.

\section{Potential methods}

To maximise innovation, organisations have to look at a wide breadth of opportunities in some detail or depth (Laursen and Salter, 2006) and therefore a longitudinal research design which facilitates this may be most appropriate. This may involve constituting a core group of innovation group research participants either organised internally and convened by an internal research manager or led by an external research consultant or company.

The innovation research participants are best separated from the core organisation particularly when the core organisation is large, well-established and set in its ways - so as to avoid the potentially inhibiting influences of corporate culture, history and mannerisms (Tushman and Nadler, 1986). Separation may be geographic, financial and hierarchical so that the innovation research group is free of close influence and feels itself to be autonomous elements which maximise creativity and idea generation.

Innovation research groups may be re-convened over time and re-constituted with core members and differing non-core members as events progress. Customers, suppliers and specialist consultants may be brought into the groups as needed and as the innovation process proceeds. Venues for the group discussions may vary according to the requirements dictated by the current research group's aims and objectives.

In terms of the identification of suitable group members, studies of innovation have found that key sources of innovation are lead users (Laursen and Salter, 2006) and therefore if those customers who often buy new products/services first can be identified from past sales, then these people should be invited to participate in the innovation research groups. Lead users tend to modify products to suit their needs and find new uses for products
Research for breakthrough innovation

799 
QMR

22,5

800

(Eisenberg, 2011) and so they can be sources of learning of innovation ideas for organisations.

Openness at an individual personality level may also be a good source of creativity and innovation (Helson et al., 1995; Marcati et al., 2008) and so research group members who are open to new experiences may be good to choose for research involvement. Openness may be identified at the research group screening phase of research participant selection for involvement in the innovation research. As there are benefits to both open discussion in groups and the use of (silent) nominal group techniques (Boddy, 2012; Paulus, 2000; Taylor et al., 1958; Paulus et al., 1995) then for optimal results both methods should be employed within innovation research. Open discussion allows innovation research group participants to bounce ideas off each other (or in the language of psychology, to foster cognitive stimulation) and other group participants can build on these. However, open discussion may also lead to the self-censorship of unique ideas for fear of ridicule and may also limit the opportunity to give voice to ideas. On the other hand silent idea generation allows for a greater number of ideas to be generated, including oddball ideas. There is therefore a place for both methods in innovation research.

\section{Hypothetical research schedule}

A hypothetical schedule for qualitative innovation group research may include the following design which starts with an idea generation stage and finishes with a product or process evaluation stage. The number of group meetings held may vary with the complexity of the product or service design and the nature of the innovations considered, in terms of their being evolutionary or revolutionary in character.

\section{Idea generation}

- Innovation group meeting 1. Group establishment - determining the core members of the innovation group and communicating what the innovation aims and objectives of the project are.

- Innovation group meeting 2. Core members and suppliers discuss ideas for innovation at a neutral venue.

- Innovation group meeting 3. Core members and customers discuss ideas for innovation at the organisation's premises.

- Innovation group meeting 4. Core members and customers discuss current product/ service usage at customer place of use.

- Innovation group meeting 5. Core members, customers and suppliers visit trade fair/ product exhibition and re-convene in the café/bar to discuss potential ideas for innovations stimulated by viewing fair/exhibition product offerings.

- Innovation group meeting 6. Core members collate all ideas for innovation and allocate idea champions to each idea.

Idea generation can involve methods such as a "find problems and then solve them" approach (Rochford, 1991) whereby manufacturers, customers and suppliers discuss any current problems they have with product or service production, usage or supply and then attempt to suggest innovations which solve those problems. For example, lists of a product's negative attributes can be generated within innovation research groups and then ideas for product enhancements may stem from considering how to overcome those negatives. 
As those vacuum cleaner manufacturers who turned down Dyson's innovative vacuum cleaner technology and design (Dyson, 2011) can testify, managers do not necessarily recognise the potential of an innovative product or service. Idea champions are therefore appointed within the innovation research group and tasked with presenting the ideas allocated to them to the whole innovation research group so that each idea at least gets a hearing. This is an attempt to avoid the rejection of good ideas and the acceptance of poor ideas.

Research for breakthrough innovation

\section{Idea evaluation}

- Idea evaluation group 1. Idea champions present ideas for innovation to core innovation group members for evaluation as to potential customer attractiveness and production feasibility. The least attractive and feasible are winnowed out.

- Idea evaluation group 2. Idea champions present the remaining ideas for innovation to core innovation group members and suppliers for evaluation as to potential production feasibility. The least feasible ideas are winnowed out.

- Idea evaluation group 3. Idea champions present ideas for innovation to core innovation group members and customers for evaluation as to potential customer attractiveness. The least attractive are winnowed out. Prototypes are made.

Within the idea evaluation stage considerations can include whether the innovation is feasible in terms of technology and finance capability, whether they may be a market for the innovation, how unique the innovation is, how long bringing the innovation to market would take and whether the firm has the ability to distribute the innovation profitably (Rochford, 1991).

It may be good practice to report on and catalogue ideas that are abandoned at this stage because subsequent changes in technology or market circumstances may make previously discarded ideas more attractive or feasible at some stage in the future (Rochford, 1991).

\section{Product or process evaluation}

- Product evaluation group 1. Prototypes of a product or process are presented to core innovation group members for evaluation as to potential customer attractiveness and production feasibility.

- Product evaluation group 2. Prototypes of a product or process are presented to core innovation group members and suppliers for evaluation as to potential materials improvement and production feasibility.

- Product evaluation group 3. Prototypes of a product or process are presented to core innovation group members and customers for evaluation as to potential customer attractiveness and possible improvement.

Prototypes can take the form of extended concepts or storyboards or actual physical products made as one-off manufactures. At this stage, the innovation research group can again ask itself, with regard to each innovation, questions such as can we make it? Can we sell it? Will customers buy it? As a means to aid product evaluation. Market research techniques can also be used to estimate whether product/service concepts and/or prototype products are attractive to potential customers.

Those products or processes which have been approved at the evaluation stage are then launched or implemented and monitored for success and for any impediments to success 
QMR

22,5

802 which need to be dealt with. Impediments may include internal resistance to success because innovation is inherently disruptive to the established order because it requires change and produces conflict within organisations (Tushman and Nadler, 1986).

Post launch, the innovation group is then tasked with something new or disbanded until needed again. For the development of a culture of maximum innovation the innovation group members who are internal to the organisation may be rewarded if successful but also allowed to take risks and fail without penalty (Tushman and Nadler, 1986) so that future ideas generation initiatives are encouraged by potential incentives but not hindered by a fear of failure.

\section{Conclusions}

Organisational innovation is beneficial to both organisations and society in terms of its socio-economic contribution to organisational longevity, success and job creation. Innovation can be incremental, synthesising or more radical in nature and involve business models, strategy, products and services, target audiences and internal processes. Innovation keeps organisations relevant to customer and environmental needs and helps prevent organisational obsolescence. Breakthrough innovation is the successful implementation of an innovative idea taken from conception to full development and launch. Such innovation can be encouraged to flourish within organisational structures if the innovation research group is given a high degree of financial, leadership and cultural autonomy. To optimise success, innovation research group membership should be diverse and include members from all stakeholder groups such as customers, suppliers and users/customers. Core innovation group members should also be diverse in terms of functional background and include personnel from, e.g. marketing, sales, production, legal and other departments so as to make sure the sources of new idea generation are both broad and deep. Stimulus materials for innovation can incorporate using various techniques such as ethnographic research methods including trips to places of customer usage and to trade fairs. Longitudinal research with stages of idea generation, idea evaluation and product or process prototype evaluation can be included in the breakthrough innovation process.

Clive Roland Boddy Department of Management, University of Tasmania, Hobart, Australia

\section{References}

Barrett, F.D. (1978), "Creativity techniques: yesterday, today, and tomorrow: Society for the advancement of management", Advanced Management Journal, Vol. 1, pp. 25-35.

Bashford, S. (2004), "10 Rules of brainstorming”, PR Week, 14th April, pp. 18-19.

Boddy, C.R. (2005a), "Groups in focus: the distinctive difference between focus group discussions and focus group interviews", Australasian Journal of Market and Social Research, Vol. 13, pp. 29-38.

Boddy, C.R. (2005b), "A rose by any other name may smell as sweet but 'group discussion' is not another name for a 'focus group' nor should it be”, Qualitative Market Research: An International Journal, Vol. 8 No. 3, pp. 248-255.

Boddy, C.R. (2011), "Hanging around with people' ethnography in marketing research and intelligence gathering", The Marketing Review, Vol. 11 No. 2, pp. 151-163.

Boddy, C.R. (2012), "The nominal group technique: an aid to brainstorming ideas in research", Qualitative Market Research: An International Journal, Vol. 15.

Boddy, C.R., Stones, N., Clark, R., Bodie, S., Williams, M., Williams, J. and Stuart, S. (2010), "Service excellence library project: Improving student and researcher access to teaching 
and learning resources. Ergo", The Journal of the Education Research Group of Adelaide, Vol. 1, pp. 53-63.

Claxton, J.D., Ritchie, J.R.B. and Zaichkowsky, J. (1980), “The nominal group technique: Its potential for consumer research", Journal of Consumer Research, Vol. 7 No. 3, pp. 308-313.

Craven, E.D., Clark, J., Cramer, M., Corwin, S.J. and Cooper, M.R. (2006), "New York-Presbyterian hospital uses six sigma to build a culture of quality and innovation", Journal of Organizational Excellence, Vol. 25 No. 4, pp. 11-19.

Design Council (2011), Design for Innovation, Design Council, London, Retrieved April.

Dunlap-Hinkler, D., Kotabe, M. and Mudambi, R. (2010), "A story of breakthrough versus incremental innovation: corporate entrepreneurship in the global pharmaceutical industry", Strategic Entrepreneurship Journal, Vol. 4 No. 2, pp. 106-127.

Dyer, J.H., Gregersen, H.B. and Christensen, C.M. (2009), "The innovator's DNA (cover story)”, Harvard Business Review, Vol. 87 No. 12, pp. 60-67.

Dyson, J. (2011), "James Dyson discusses innovation, bringing new products to market and more edison nation", Directed by DYSON, J, available at: www.youtube.com/watch?v=PzCU7fiTXEw

Eisenberg, I. (2011), "Lead-user research for breakthrough innovation", Research-Technology Management, Vol. 54 No. 1, pp. 50-58.

Fisher, R.J. (1993), "Social desirability bias and the validity of indirect questioning", Journal of Consumer Research, Vol. 20 No. 2, pp. 303-315.

Gregerman, I.B. (1981), "Knowledge worker productivity measurement through the nominal group technique", Industrial Management, Vol. 23, pp. 5-8.

Helson, R., Roberts, B. and Agronick, G. (1995), "Enduringness and change in creative personality and the prediction of occupational creativity", Journal of Personality and Social Psychology, Vol. 69 No. 6, pp. 1173-1183.

Hollins, B. (1999), "Brainstorming products for the long-term future", Creativity and Innovation Management, Vol. 8, pp. 286-293.

Kuratko, D.F. and Morris, M.H. (2018), "Corporate entrepreneurship: a critical challenge for educators and researchers", Entrepreneurship Education and Pedagogy, Vol. 1 No. 1, pp. $42-60$.

Laursen, K. and Salter, A. (2006), "Open for innovation: the role of openness in explaining innovation performance among UK manufacturing firms", Strategic Management Journal, Vol. 27 No. 2, pp. 131-150.

Marcati, A., Guido, G. and Peluso, A.M. (2008), "The role of SME entrepreneurs' innovativeness and personality in the adoption of innovations", Research Policy, Vol. 37 No. 9, pp. 1579-1590.

Martins, E.C. and Terblanche, F. (2003), "Building organisational culture that stimulates creativity and innovation”, European Journal of Innovation Management, Vol. 6 No. 1, pp. 64-74.

Østergaard, C.R., Timmermans, B. and Kristinsson, K. (2011), "Does a different view create something new? The effect of employee diversity on innovation", Research Policy, Vol. 40 No. 3, pp. 500-509.

Paulus, P.B. (2000), "Groups, teams, and creativity: the creative potential of idea-generating groups", Applied Psychology, Vol. 49 No. 2, pp. 237-263.

Paulus, P.B., Larey, T.S. and Ortega, A.H. (1995), "Performance and perceptions of brainstormers in an organizational setting", Basic and Applied Social Psychology, Vol. 17, pp. 249-265.

Rochford, L. (1991), "Generating and screening new products ideas", Industrial Marketing Management, Vol. 20 No. 4, pp. 287-296.
Research for breakthrough innovation

803 
QMR

22,5

804
Roper, S. (1997), "Product innovation and small business growth: a comparison of the strategies of German, UK and Irish companies", Small Business Economics, Vol. 9 No. 6 , pp. 523-537.

Schwartz, A.E. (1991), "Using brainstorming to identify creative solutions", Supervisory Management, Vol. 36, p. 4.

Stafford, M.R. (1993), "Participant observation and the pursuit of truth: methodological and ethical considerations", Journal of the Market Research Society, Vol. 35 No. 1, pp. 63-76.

Taylor, D.W., Berry, P.C. and Block, C.H. (1958), "Does group participation when using brainstorming facilitate or inhibit creative thinking?", Administrative Science Quarterly, Vol. 3 No. 1, pp. 23-47.

Tushman, M. and Nadler, D. (1986), "Organizing for innovation", California Management Review, Vol. 28 No. 3, pp. 74-92.

West, M.A. (2002), "Sparkling fountains or stagnant ponds: an integrative model of creativity and innovation implementation in work groups", Applied Psychology, Vol. 51 No. 3, pp. 355-387. 